\title{
Region Asymmetric Polymers Based on Fluorinated Benzothiadiazole-Benzodithiophene for Polymer Solar Cells with High Open-Circuit Voltage
}

\author{
Caijun Liu ${ }^{1}$, Guoyue Gan ${ }^{1}$, Zhanfeng Li ${ }^{1,2, *}$, Na Sun ${ }^{1}$, Xueqiao Li ${ }^{1}$, \\ Yahui Tong ${ }^{1}$, Hua Wang ${ }^{3}$, and Yuying Hao ${ }^{1, *}$
}

1 Key Laboratory of Advanced Transducers and Intelligent Control System, Ministry of Education and Shanxi Province, College of Physics and Optoelectronics, Taiyuan University of Technology, Taiyuan 030024, P. R. China

2 Center of Super-Diamond and Advanced Films (COSDAF) and Department of Chemistry, City University of Hong Kong, Hong Kong 999077, P. R. China

3 Key Laboratory of Interface Science and Engineering in Advanced Materials, Taiyuan University of Technology, Taiyuan 030024, P. R. China

* Correspondence: lizhanfeng@tyut.edu.cn (Z. Li); haoyuying@tyut.edu.cn (Y. Hao).

\begin{abstract}
Two region asymmetric polymers PR2F and PR1F with three repeat units of A-D-A, $\pi$-D-A, and $\pi$-D- $\pi$ along the polymer backbone were attained by polymerizing different fluorinated benzothiadiazole-thiophene units, FBT-T and 2FBT-T units (A- $\pi$ ), with benzodithiophene unit (D), respectively. Here, the new region asymmetric polymers were in contrast to the traditional polymers featuring a $\mathrm{D}-\mathrm{A}$ or $\mathrm{D}-\pi-\mathrm{A}-\pi$ backbone. Both the region asymmetric polymers showed a low lying of HOMO energy level in relation to that of the $\mathrm{PC}_{61} \mathrm{BM}$ acceptor and then obtained the high open-circuit voltage of $\sim 1 \mathrm{~V}$ in both PR2F and PR1F devices. Bulk-heterojunction devices based on PR2F with difluorinated BT exhibited an appreciable power conversion efficiency (PCE) of $4.73 \%$
\end{abstract}


due to the relatively high and balanced charge carrier mobilities, while the mono-fluorinated BT polymer PR1F-based devices gave a lower PCE of $2.92 \%$. These results indicate that the region asymmetric conjugated polymer is a promising class of materials for polymer solar cell applications, and it is significant to further understand the influence of polymer structure on optoelectronic properties.

Keywords: polymer solar cells; region asymmetric polymers; fluorinated benzothiadiazole

\section{Introduction}

Solution-processed bulk-heterojunction (BHJ) polymer solar cells (PSCs) have been extensively investigated in recent years due to their unique advantages such as light weight, low-cost, large-area fabrication, solution processability and mechanical flexibility [1-5]. Over the past decade, great efforts have been spent to maximize the performance of PSCs, and the power conversion efficiencies (PCEs) of PSCs exceeding 14\% have been demonstrated in single-junction cell [6], which heralds the bright future of practical application of PSCs [7-10]. The active layer materials are of vital importance because they determine not only the maximum attainable current density $\left(J_{\mathrm{SC}}\right)$, but also the highest open-circuit voltage $\left(V_{\mathrm{OC}}\right)$ and the fill factor $(\mathrm{FF})$ of PSCs [11,12]. It was well-studied that deep highest occupied molecular orbital (HOMO) energy level for high $V_{\mathrm{OC}}$ and sufficient offset of lowest unoccupied molecular orbital (LUMO) energy level between polymer donor and fullerene acceptor are important approach to achieve high performance PSCs [13]. The molecular structure of the polymers enable control of optoelectronic properties [14-16], such as optical gaps and orbital energy levels, as well as relevant bulk properties (charge carrier mobility and film morphology), which combine to dictate the photovoltaic device performance $[17,18]$. 
For achieving these desired properties, a common design strategy of polymer donors that incorporated molecular electron donor (D) and acceptor (A) units in an alternating manner to create the traditional architecture (D-A or $\mathrm{D}-\pi-\mathrm{A}-\pi)$ was proposed [19-21]. Recently, many results showed that the introduction of asymmetric monomer into the regioregular polymers could typically achieve a greater degree of crystallinity and thus higher device performance $[15,22,23]$. For example, Zhou and co-workers reported that the random polymer 2TRA achieved a substantially higher PCE (8.8\%) than the regioregular polymer 2TRR (5.1\%), where both 2TRA and 2TRR contained the same type and proportion of subunits but with different connectivity [24]. Yang's group have designed and synthesized a new type of polymer P1T with a repeat unit of $\mathrm{D}-\pi-\mathrm{A}$ or $\mathrm{D}-\pi$ by breaking the traditional $\mathrm{D}-\mathrm{A}$ or $\mathrm{D}-\pi-\mathrm{A}-\pi$ configuration. And the asymmetric polymer P1T device exhibited the optimal PCE with an active layer thickness of over $200 \mathrm{~nm}$ [23]. Therefore, to construct a novel asymmetric polymer would expand its potential use in high-efficiency photovoltaic applications.

Hence, we designed two region asymmetric polymers PR2F and PR1F by introducing the classical benzo[1,2-b:4,5- $\left.b^{\prime}\right]$-dithiophene (BDT) and fluorinated benzo[2,1,3]thiadiazole (2FBT or FBT) as D and A units, respectively. The new A segments were achieved by coupling one aromatic thiophene $(\mathrm{T})$ unit as the " $\pi$-spacer" to the 2FBT and FBT units to construct the FBT-T and 2FBT-T moieties $(\mathrm{A}-\pi)$, respectively, which obviously differs from the traditional $A$ and $\pi-\mathrm{A}-\pi$ units in the typical conjugated polymers [23]. The molecular structures of the repeat units and relevant polymers PR2F and PR1F are shown in Figure 1 and Scheme 1, which highlights three repeat units of A-D-A, $\pi$-D-A, and $\pi$-D- $\pi$ along the polymer backbone for our molecular design. Therefore, the two region asymmetric polymers differ from the conventional polymers featuring a $\mathrm{D}-\mathrm{A}$ or $\mathrm{D}-\pi-\mathrm{A}-\pi$ backbone. Both polymers show a low lying of HOMO energy level in relation to that of the $\mathrm{PC}_{61} \mathrm{BM}$ acceptor and then obtain the high $V_{\mathrm{OC}}$ of $\sim 1$ $\mathrm{V}$ in both PR2F and PR1F devices. The PR2F:PC ${ }_{61} \mathrm{BM}$ devices gave an appreciable PCE 
of $4.73 \%$, while the PR1F/PC ${ }_{61} \mathrm{BM}$ blend devices exhibited a lower PCE of $2.92 \%$. It can be seen that the region asymmetric polymer is a novel idea to design active layer donor materials for achieving high performance solar cells, and it is significant to further understand the influence of polymer structure on optoelectronic properties.

PR1F
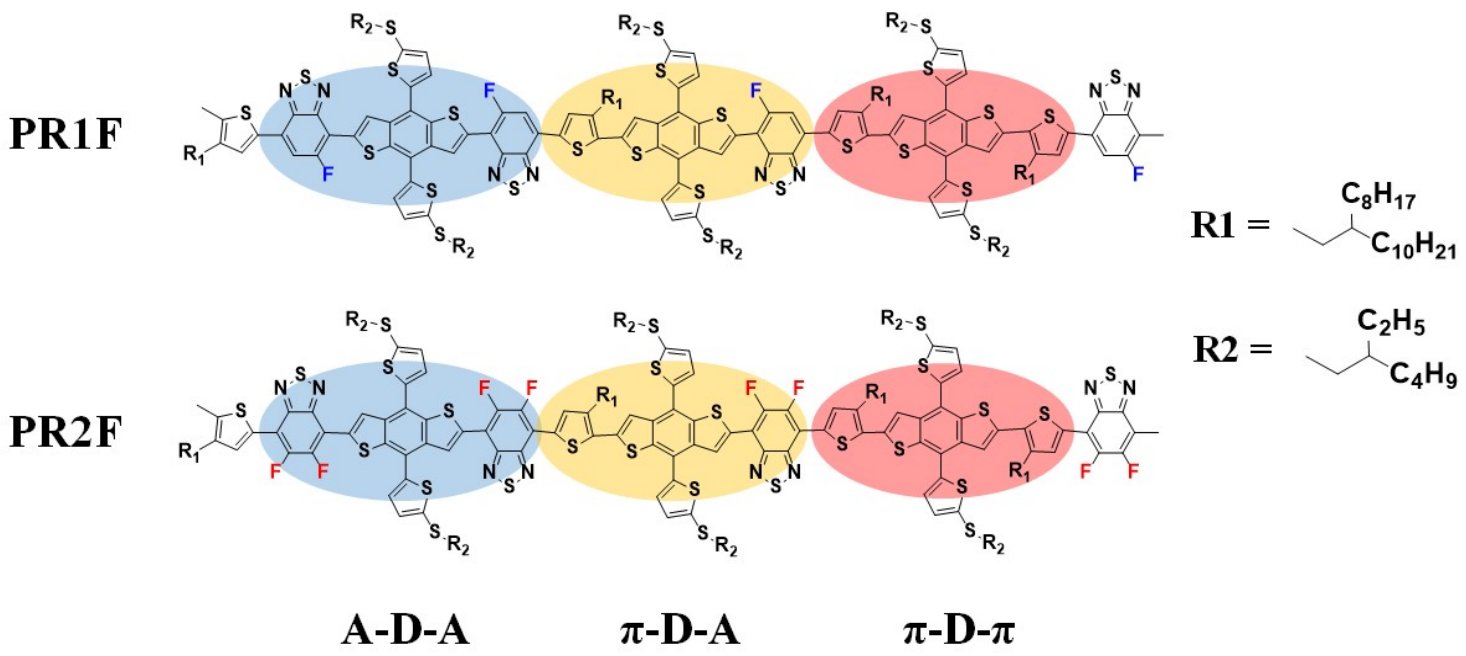

Figure 1. The molecular structure of repeat unit of PR1F and PR2F.

\section{Results and discussion}

\subsection{Synthesis and characterization of the polymers}

The detailed synthesis procedure for four A- $\pi$ monomers (M1, M2, M3 and M4) and relevant polymers (PR2F and PR1F) is shown in Scheme 1 and described in the Experimental section. The key monomers M1 and M2 were prepared using Stille polymerization with the dibrominated FBT/2FBT and the mono-stannylated $\mathrm{T}$ with a ratio of $1: 1$ in the presence of $\mathrm{Pd}\left(\mathrm{PPh}_{3}\right)_{4}$ as a catalyst, in $68 \%$ yield. Bromination of $\mathrm{M} 1$ and M2 with NBS gave the dibrominated FBT-T/2FBT-T monomer (M3 or M4) in high yield of 93\%. The final polymers PR2F and PR1F were also synthesized via stille

polymerization between the distannylated BDT monomer and the dibrominated FBT-T/2FBT-T monomer (M3 or M4) in good yield (80\%). It should be noted that each 
BDT end could chemically couple with a $\mathrm{T}$ or FBT/2FBT end in the FBT-T/2FBT-T segments, so the same subunits ( $\mathrm{T}$ and FBT-T/2FBT-T) can be arranged in different configurations along the polymer backbone (Fig. 1). The number-average molecular weights $\left(M_{\mathrm{n}}\right)$ and polydispersity index (PDI) of the regional asymmetry polymers PR2F and PR1F were analyzed by gel permeation chromatography (GPC) with THF as the eluent. The $M_{\mathrm{n}}$ of PR2F and PR1F are $24.9 \mathrm{kDa}$ and $61.9 \mathrm{kDa}$, respectively, corresponding to PDI values of 3.31 and 1.91. The lower molecular weight and the larger PDI value for PR2F might be due to its limited solubility.
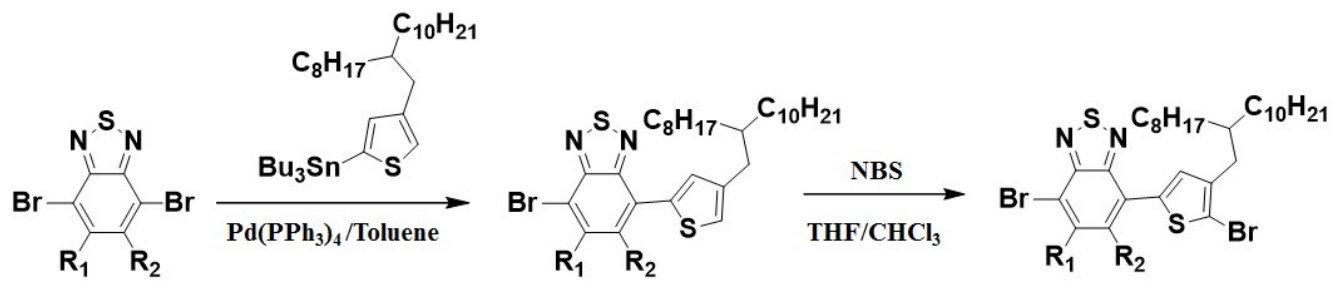

$$
\begin{aligned}
& M 1=(R 1=F, R 2=F) \\
& M 2=(R 1=F, R 2=H)
\end{aligned}
$$

$$
\mathrm{M3}=(\mathrm{R} 1=\mathrm{F}, \mathrm{R} 2=\mathrm{F})
$$$$
\mathrm{M} 4=(\mathrm{R} 1=\mathrm{F}, \mathrm{R} 2=\mathrm{H})
$$

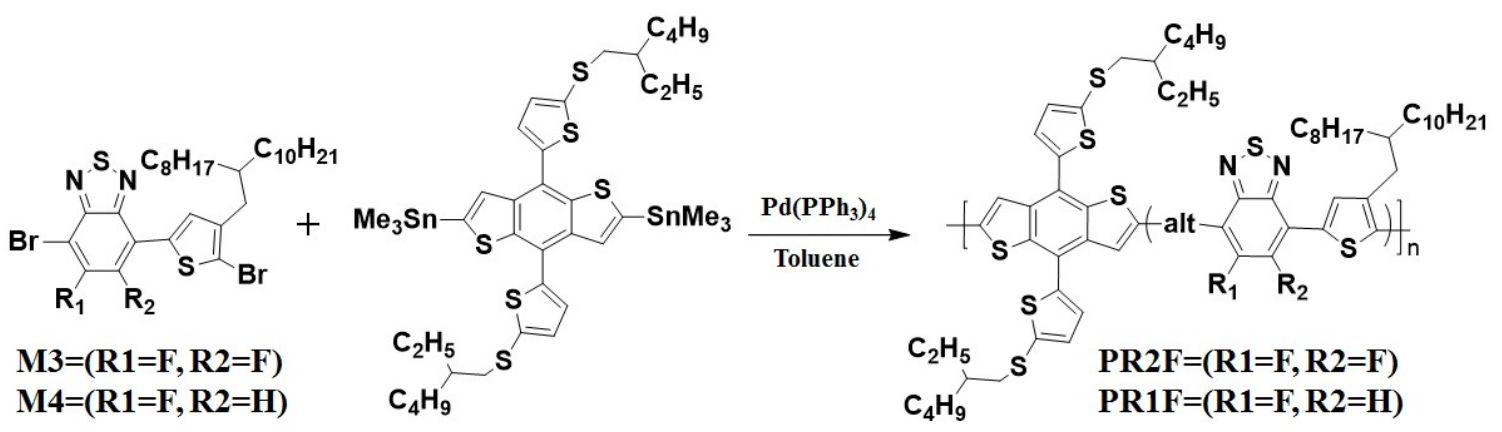

Scheme 1. Synthetic routes and chemical structures of the polymers PR2F and PR1F.

A theoretical calculation based on density functional theory (DFT) calculations of Gaussian 09 with B3LYP functional and 6-31G basis sets was carried out to analyze different configurations along the polymer backbone and the electron density distribution at the LUMO and HOMO energy levels of two polymers. Due to the characteristics of its regional asymmetry, the skeleton has no fixed repeating unit compared with the traditional regular structure and random structure. In this work, we only calculated one of the arrangements about the three different ways of connecting. The three distinct repeat units in its backbone of each polymer under ideal condition with the alkyl chains 
substituted by methyl groups, which were selected for ease of calculation. As illustrated in Figure 2, both of the optimized structures of the repeat building blocks of PR2F and PR1F showed excellent co-planarity with the dihedral angle of less than $10^{\circ}$ between the BDT, $\mathrm{T}$ and the fluorinated BT (FBT or 2FBT) units. Such a good co-planarity and electron distribution in the frontier molecular orbitals on the PR1F and PR2F backbones would contribute to the efficiency of the charge transport along the extended $\pi$-conjugation path. The HOMO electron density of the distinct repeat units in PR2F and PR1F is delocalized over the whole polymers backbone basically, while the electron density in the LUMO is primarily concentrated on the fluorinated BT groups. There is hardly any electron density distribution on the alkylthio-T conjugated side chains of the repeat building blocks of the PR2F and PR1F. The simulated HOMO for PR2F and PR1F are -5.05 and $-4.95 \mathrm{eV}$, and the simulated LUMO for PR2F and PR1F are -3.09 and $-3.04 \mathrm{eV}$, respectively.

\section{PR2F}

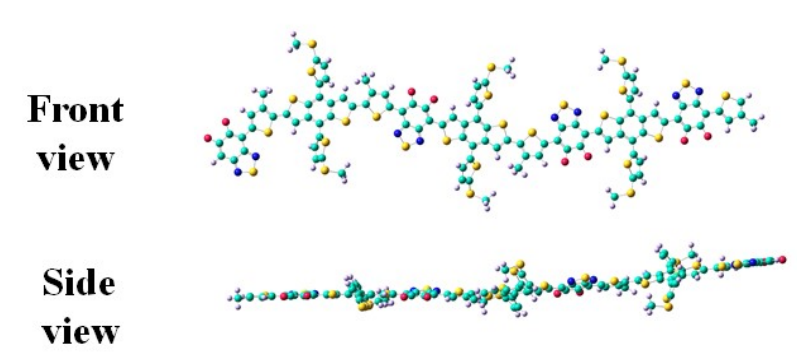

HOMO

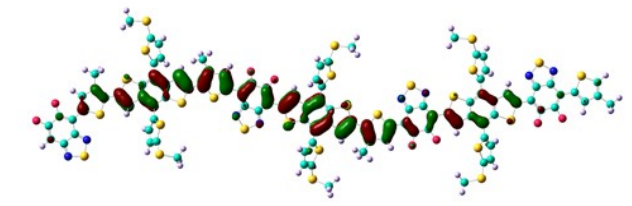

LUMO

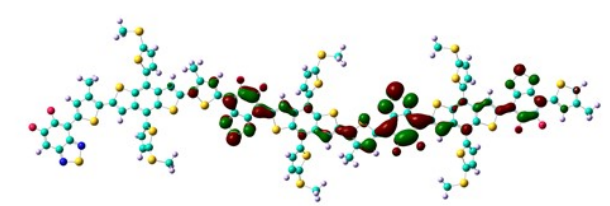

\section{PR1F}
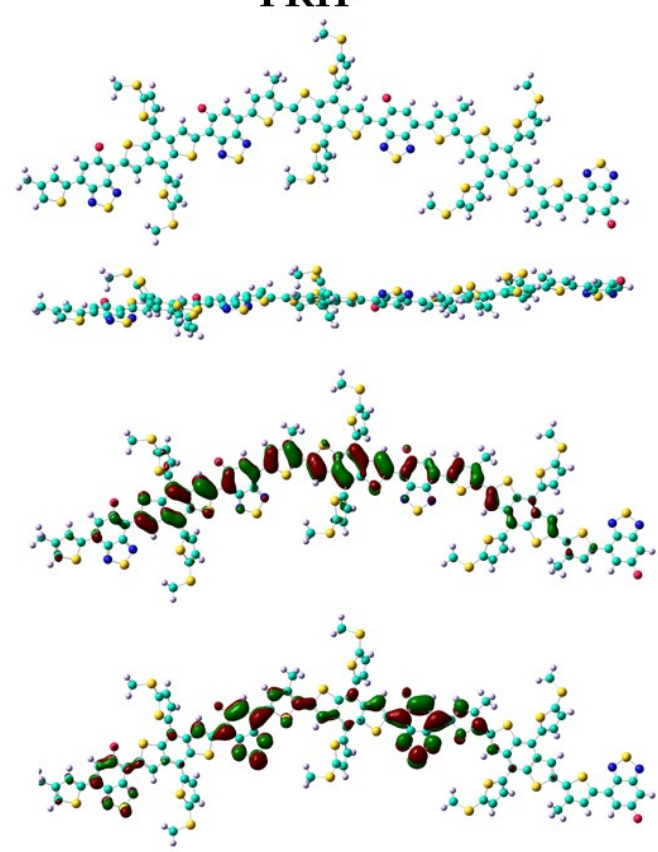

Figure 2. Front view and side view of optimized geometries, the frontier molecular orbital obtained from DFT calculations on the PR2F and PR1F backbone units with a chain length $n=1$. (Color code: light blue $(\mathrm{C})$, gray $(\mathrm{H})$, red $(\mathrm{F})$, blue $(\mathrm{N})$, yellow $(\mathrm{S}))$. 


\subsection{Optical, electrochemical and thermal properties}

Figure 3 shows the absorption spectra of PR2F and PR1F in chloroform solution and thin solid film. From solution to film, the two polymers demonstrated strong and broad absorption spectra in the wavelength region from $300 \mathrm{~nm}$ to $750 \mathrm{~nm}$ and became broader and red-shifted due to the aggregation of polymer chains in the solid state [25]. The well-defined absorption peaks both in the solution and thin films with a vibronic shoulder in the longer wavelength range imply the existence of ordered aggregation and strong $\pi-\pi$ stacking induced by $\mathrm{F}$ atoms. Corresponding to the intramolecular charge transfer interaction between the $\mathrm{D}$ and $\mathrm{A}$ units, the two absorption peaks of the film at the long wavelength implicate a high degree of molecular order within the film [26]. The optical band gaps $\left(E_{\mathrm{g}}{ }^{\mathrm{opt}}\right)$ of PR2F and PR1F were calculated from the absorption edge of the thin films to be 1.75 and $1.73 \mathrm{eV}$, respectively.
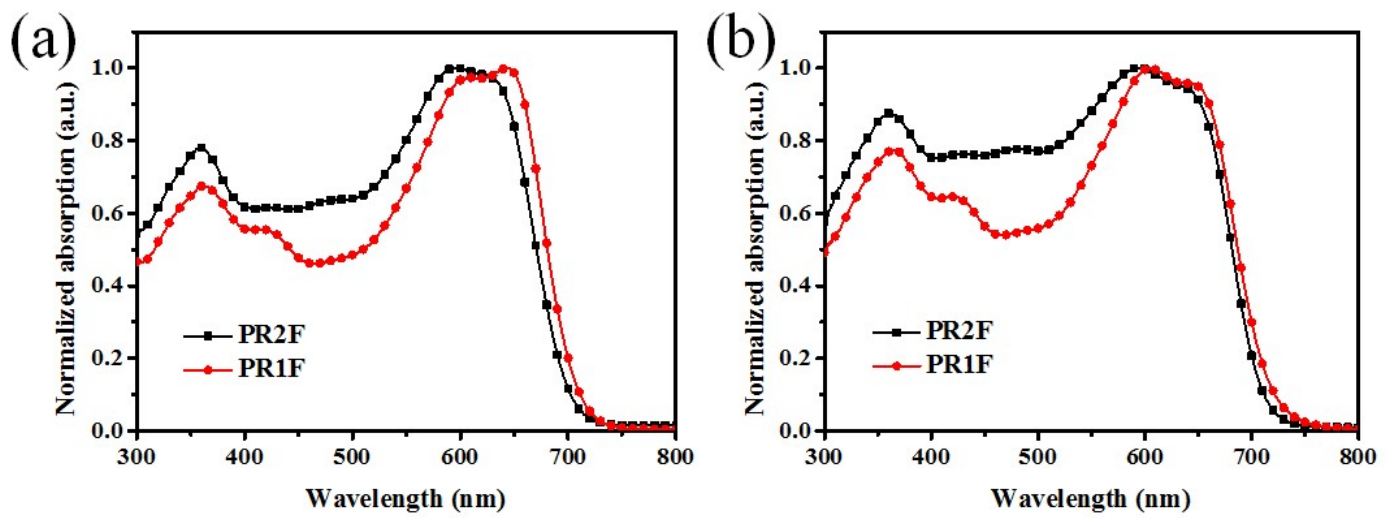

Figure 3. Normalized absorption spectra of the copolymers in chloroform solution (a) and in thin film (b).

Cyclic voltammetry (CV) was carried out to estimate the electronic energy levels of the two conjugated polymers, and the HOMO and LUMO energy levels were estimated from the onset oxidation $\left(E_{\mathrm{ox}}{ }^{\text {on }}\right)$ and reduction $\left(E_{\mathrm{red}}{ }^{\mathrm{on}}\right)$ potentials by assuming the energy level of ferrocene/ferrocenium $\left(\mathrm{Fc} / \mathrm{Fc}^{+}\right)$to be $-4.8 \mathrm{eV}$ below the vacuum level. The LUMO and HOMO levels of PR2F and PR1F are $-3.89 /-5.34 \mathrm{eV}$ and $-3.87 /-5.29 \mathrm{eV}$, respectively, 
which agree with the results of the DFT calculations, as shown in Figure 4 and Table 1. When the number of $\mathrm{F}$ atoms per repeat segment was increased from 1 to 2, the enhanced effective density of the fluorinated BT units in the polymer backbone led to lower HOMO and LUMO levels. Consequently, a high $V_{\mathrm{OC}}$ in the PSC device is expected. The electronchemical bandgap values $\left(E_{\mathrm{g}}{ }^{\mathrm{CV}}\right)$ estimated by $E_{\mathrm{g}}{ }^{\mathrm{CV}}=\mathrm{LUMO}-\mathrm{HOMO}(\mathrm{eV})$ were very similar as 1.45 and $1.43 \mathrm{eV}$ for PR2F and PR1F, respectively. Their respective energy levels diagram is outlined in Fig. 4b. The HOMO energy levels of PR2F and PR1F are generally lower than that of ITO; meanwhile, the LUMO energy levels of PR2F and PR1F are slightly higher than that of $\mathrm{PC}_{61} \mathrm{BM}$ and the LUMO energy offsets are about $0.4 \mathrm{eV}$. Such energy alignment not only allows charge collection from the anode but also provides sufficient driving force for transferring the excited electrons to $\mathrm{PC}_{61} \mathrm{BM}$ acceptor materials.
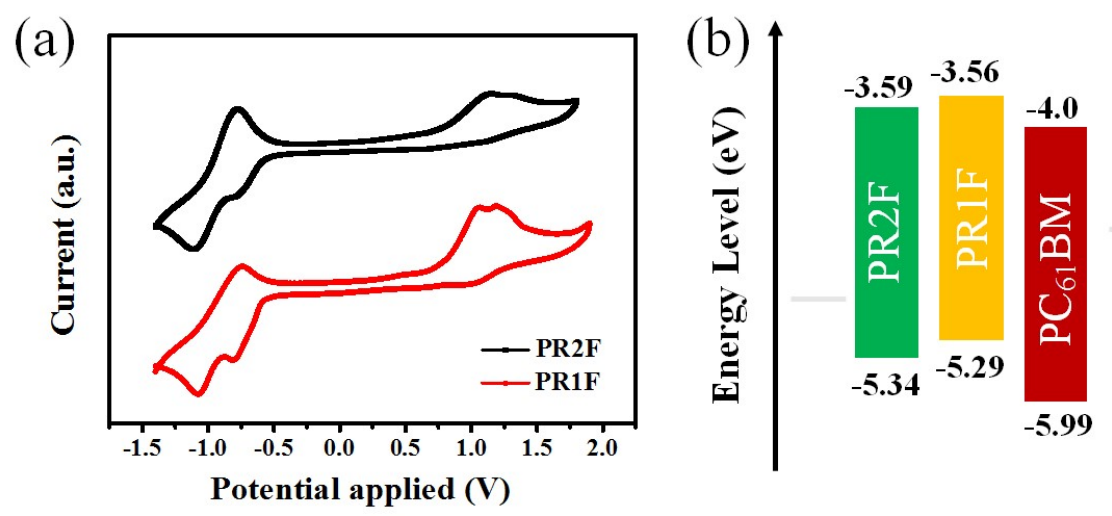

Figure 4. (a) $\mathrm{CV}$ curves of thin films of the polymers in $\mathrm{CH}_{3} \mathrm{CN} / 0.1 \mathrm{M} \mathrm{Bu}_{4} \mathrm{NPF}_{6}$ at a scan rate of 50 $\mathrm{mV} \mathrm{s}^{-1}$. (b) Energy level of PR2F, PR1F and $\mathrm{PC}_{61} \mathrm{BM}$.

The thermal properties of the polymers were investigated by thermogravimetric analysis (TGA), as shown in Figure 5 and Table 1. It is noteworthy that the decomposition temperature $\left(T_{\mathrm{d}}\right)$ estimated from onset point of the $5 \%$ weight loss of polymer PR2F $\left(339^{\circ} \mathrm{C}\right)$ was higher than that of PR1F $\left(323^{\circ} \mathrm{C}\right)$. The thermal stabilities of PR2F and PR1F are good enough for their application in PSCs. 


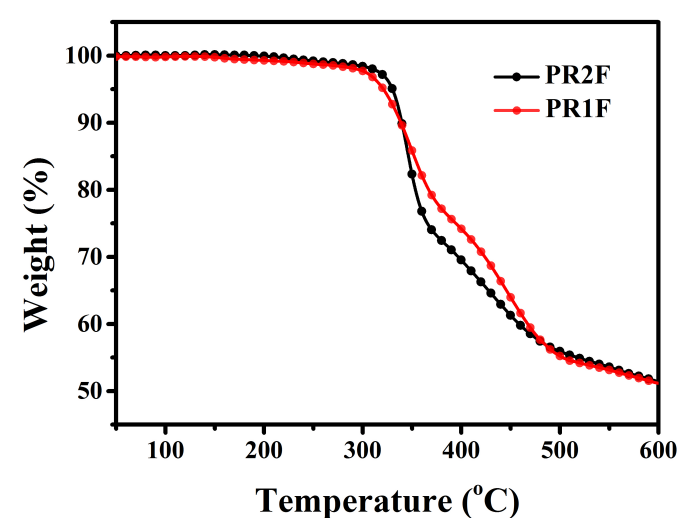

Figure 5. TGA plot of PR2F and PR1F under the nitrogen atmosphere.

Table 1. Characteristics of polymers.

\begin{tabular}{|c|c|c|c|c|c|c|c|c|}
\hline polymer & $\begin{array}{c}M_{\mathrm{n}}(\mathbf{k D a}) \\
\quad / \mathrm{PDI}\end{array}$ & $\begin{array}{l}\lambda_{\max }{ }^{\mathrm{sol}} \\
(\mathrm{nm})^{\mathrm{a}}\end{array}$ & $\begin{array}{c}\lambda_{\max }{ }^{\text {film }} \\
(\mathrm{nm})^{\mathrm{b}}\end{array}$ & $\begin{array}{l}\lambda_{\text {onset }}{ }^{\text {film }} \\
(\mathbf{n m})^{\mathrm{c}}\end{array}$ & $\begin{array}{l}E_{\mathrm{g}}{ }^{\mathrm{opt}} \\
(\mathrm{eV})^{\mathrm{d}}\end{array}$ & $\begin{array}{c}T_{\mathrm{d}} \\
\left({ }^{\circ} \mathrm{C}\right)\end{array}$ & $\begin{array}{c}\text { HOMO/LUMO } \\
E_{\mathrm{g}}{ }^{\mathrm{CV}}(\mathrm{eV})^{\mathrm{d}}\end{array}$ & $\begin{array}{c}\text { HOMO/LUMO } \\
\left(\Delta E_{\text {HOMо-LUMO }}(\mathrm{eV})^{\mathrm{e}}\right.\end{array}$ \\
\hline PR2F & $24.9 / 3.31$ & 600 & 618 & 710 & 1.75 & 339 & $-5.34 /-3.89(1.45)$ & $-5.05 /-3.09(1.96)$ \\
\hline PR1F & $61.9 / 1.92$ & 608 & 620 & 718 & 1.73 & 323 & $-5.29 /-3.87(1.42)$ & $-4.95 /-3.04(1.91)$ \\
\hline
\end{tabular}

${ }^{\mathbf{a}}$ Absorption data were collected in $\mathrm{CHCl}_{3}$ solution; ${ }^{\mathbf{b}}$ Absorption data were collected in thin film; ${ }^{\mathbf{c}}$ $E_{\mathrm{g}}{ }^{\text {opt }}=1240 / \lambda_{\text {onset; }}{ }^{\mathbf{d}}$ The HOMO and LUMO energies were determined from CV, $E_{\mathrm{g}}{ }^{\mathrm{CV}}=\mathrm{LUMO}-$ HOMO; ${ }^{\mathbf{e}}$ Values from DFT calculation.

\subsection{Photovoltaic properties}

A conventional PSC architecture of ITO/PEDOT:PSS/active layer/LiF/Al was fabricated to evaluate the photovoltaic performance of the two polymers PR2F and PR1F as donor materials. It was prepared by spin-coating the blend solution of polymer:PC $61 \mathrm{BM}(1: 1.5, \mathrm{w} / \mathrm{w})$ in chlorobenzene with $2 \% 1,8$-diiodooctane (DIO) as the additive. Typical current density-voltage $(J-V)$ curves and the corresponding external quantum efficiency (EQE) curves are presented in Figure 6 and the key device parameters of the PSCs with and without solution vapour annealing (SVA) are summarized in Table 2. Compared with the PR1F:PC ${ }_{61} \mathrm{BM}$ device without SVA, which 
delivered a low efficiency of $2.58 \%$, the PR2F:PC ${ }_{61} \mathrm{BM}$ device showed a remarkable increase in PCE to $3.26 \%$ with a $V_{\mathrm{OC}}$ of $0.97 \mathrm{~V}$, a $J_{\mathrm{SC}}$ of $7.08 \mathrm{~mA} \mathrm{~cm}^{-2}$, and an FF of 0.48 . In addition, after SVA with methanol, the overall performance of the devices from both polymer donor materials was enhanced as a result of the enhancement of $J_{\mathrm{SC}}$. It is shown that the PSCs based on PR1F showed a PCE of $2.92 \%$, with a $V_{\mathrm{OC}}$ of $0.93 \mathrm{~V}$, a $J_{\mathrm{SC}}$ of $7.97 \mathrm{~mA} \mathrm{~cm}^{-2}$, and an FF of 0.39, while PR2F-based device substantially improves the efficiency to $4.73 \%$, with a $V_{\mathrm{OC}}$ of $0.98 \mathrm{~V}, J_{\mathrm{SC}}$ of $10.01 \mathrm{~mA} \mathrm{~cm}{ }^{-2}$, and FF of 0.48 . The $V_{\mathrm{OC}}$, however, is seen to be higher than that of typical devices made from PCBM [27], approaching $1 \mathrm{~V}$ for both PR2F and PR1F devices, which can be attributed to the low lying of HOMO energy level induced by the F substitution onto the polymer backbone [28].
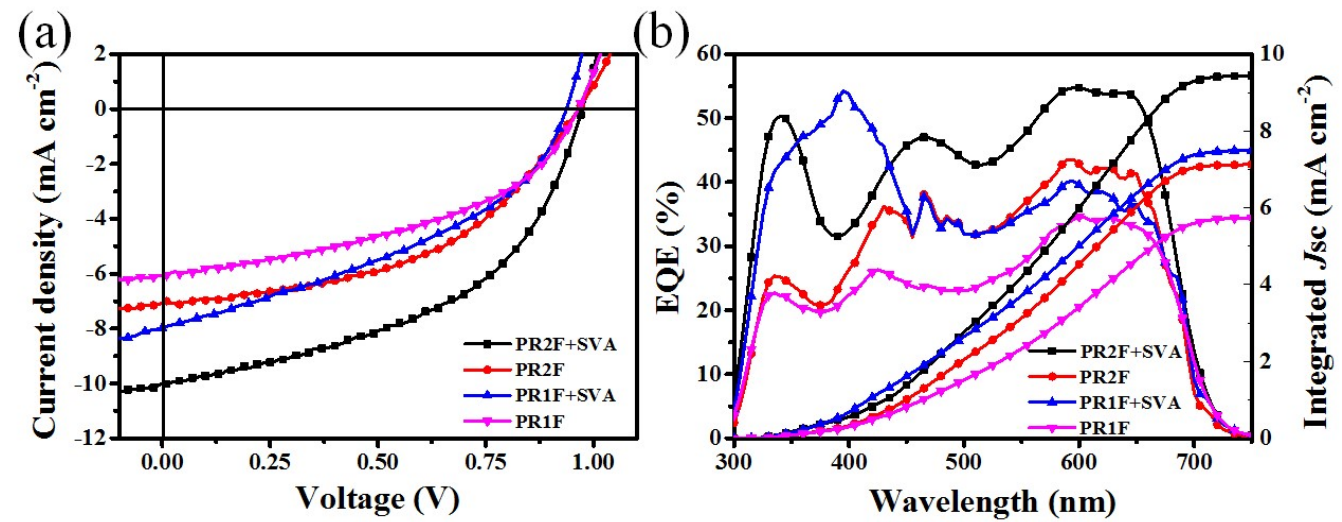

Figure 6. (a) $J-V$ curves of the PSCs under illumimination of AM $1.5 \mathrm{G}, 100 \mathrm{~mW} \mathrm{~cm} \mathrm{~cm}^{-2}$. (b) EQE curves of the corresponding devices.

To corroborate the measured $J_{\mathrm{SC}}$ results, the EQE of the PSCs based on polymers:PC ${ }_{61} \mathrm{BM}(1: 1.5, \mathrm{w} / \mathrm{w})$ with and without SVA was measured under monochromatic light, as shown in Figure 6b. All devices without SVA exhibited a response range from 300 to $700 \mathrm{~nm}$, with a maximum EQE value of 0.43 at $600 \mathrm{~nm}$. Moreover, SVA produced a significant improvement in the EQE in the wavelength range of 300-700 nm. The device with PR2F showed substantially higher photoresponse than that with PR1F-based device, which contributed a lot to the high $J_{\mathrm{SC}}$ and stronger film 
absorption. The $J_{\mathrm{SC}}$ of PR2F:PC ${ }_{61} \mathrm{BM}$ and PR1F:PC ${ }_{61} \mathrm{BM}$ with SVA estimated by the integration of the EQE spectrum agrees with the values from the $J-V$ measurement.

Table 2. Photovoltaic properties of PSCs based on PR2F and PR1F.

\begin{tabular}{|c|c|c|c|c|c|c|}
\hline Active layer & SVA & $\begin{array}{l}V_{\text {oc }} \\
(V) \\
\end{array}$ & $\begin{array}{c}J_{\text {sc }} \\
\left(\mathrm{mA} \mathrm{cm}^{-2}\right)\end{array}$ & 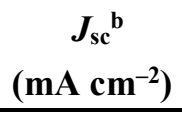 & FF & $\begin{array}{l}\text { PCE } \\
(\%)\end{array}$ \\
\hline PR2F & $\mathrm{w}$ & 0.98 & 10.01 & 9.45 & 0.48 & 4.73 \\
\hline PR2F & w/o & 0.97 & 7.08 & 7.13 & 0.48 & 3.26 \\
\hline PR1F & $\mathrm{w}$ & 0.93 & 7.97 & 7.50 & 0.39 & 2.92 \\
\hline PR1F & w/o & 0.96 & 6.06 & 5.74 & 0.44 & 2.59 \\
\hline
\end{tabular}

${ }^{\mathbf{a}}$ Average PCEs in parentheses were obtained from more than 20 devices; ${ }^{\mathbf{b}}$ The EQE-integrated $J_{\mathrm{sc}}$.

\subsection{Charge transport properties}

High charge carrier mobility and balanced charge-carrier transport are very important for high performance photovoltaic materials in PSCs [29,30]. To compare their hole and electron transport properties, we first measured vertical transport in blend films using the space-charge-limited current (SCLC) model and the hole-only and electron-only devices with the structure of ITO/PEDOT:PSS/polymer:PC ${ }_{61} \mathrm{BM} / \mathrm{MoO}_{3} / \mathrm{Al}$ and ITO/ZnO/polymer:PC ${ }_{61} \mathrm{BM} / \mathrm{LiF} / \mathrm{Al}$ were fabricated [20], respectively. As shown in Figure 7 , the hole and electron mobilities $\left(\mu_{\mathrm{h}}\right.$ and $\left.\mu_{\mathrm{e}}\right)$ were estimated to be $1.46 \times 10^{-3}$ and $2.09 \times 10^{-3} \mathrm{~cm}^{2} \mathrm{~V}^{-1} \mathrm{~s}^{-1}$ for PR2F:PC ${ }_{61} \mathrm{BM}$ blend, and $4.05 \times 10^{-5}$ and $7.74 \times 10^{-3} \mathrm{~cm}^{2} \mathrm{~V}^{-1}$ $\mathrm{s}^{-1}$ for PR1F:PC ${ }_{61} \mathrm{BM}$ blend. The relatively high and balanced charge carrier mobilities of PR2F-based device indicates that the generated electrons and holes transfer efficiently in the active blend layer, thus giving rise to higher $J_{\mathrm{SC}}$ and FF than those of PR1F-based device $[31,32]$. 

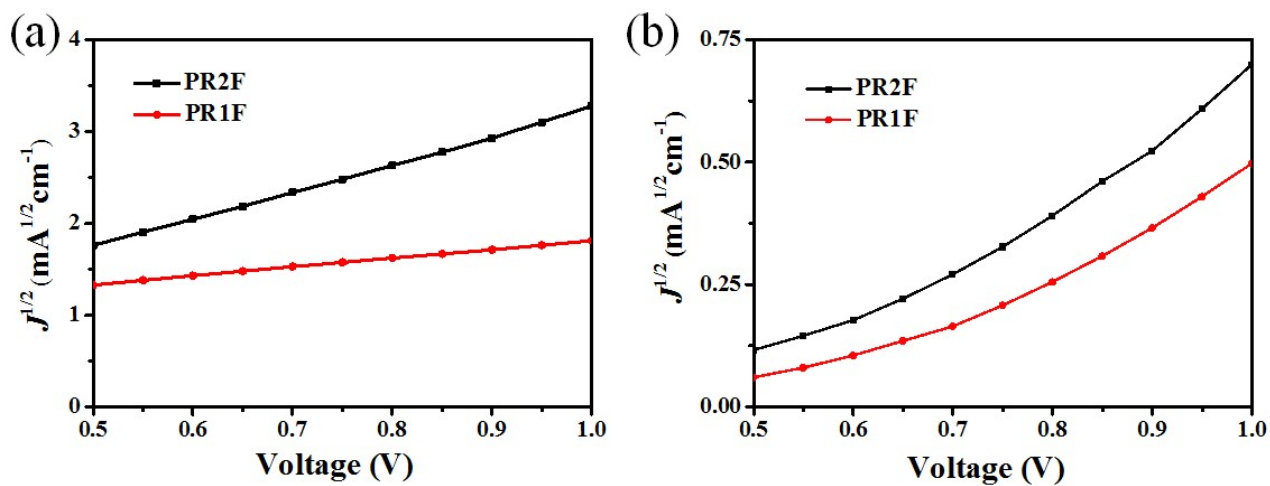

Figure 7. (a) Hole-only devices based on PR2F:PC ${ }_{61} \mathrm{BM}(1: 1.5, \mathrm{w} / \mathrm{w})$ and $\mathrm{PR} 1 \mathrm{~F}: \mathrm{PC}_{61} \mathrm{BM}(1: 1.5, \mathrm{w} / \mathrm{w})$. (b) Electron-only devices based on PR2F:PC ${ }_{61} \mathrm{BM}(1: 1.5, \mathrm{w} / \mathrm{w})$ and PR1F:PC ${ }_{61} \mathrm{BM}(1: 1.5, \mathrm{w} / \mathrm{w})$.

We also measure the fraction of absorption photons in blended thin films based on PR2F and PR1 (Figure 8a). It was indicated that the PR2F:PC ${ }_{61} \mathrm{BM}$ blend film showed the stronger absorption intensity from 300 to $660 \mathrm{~nm}$. The photoluminescence (PL) emission spectra were analyzed to study the charge transfer behavior within the blend films. The emission spectra of the pure polymer and polymer: $\mathrm{PC}_{61} \mathrm{BM}$ blend films are obtained and shown in Figure 8b. The pure PR2F and PR1F films exhibited a strong PL response compared with polymers blend with $\mathrm{PC}_{61} \mathrm{BM}$ ranging from 650 to $850 \mathrm{~nm}$ with the main peaks at 710 and $725 \mathrm{~nm}$, respectively. When blended with $\mathrm{PC}_{61} \mathrm{BM}$, the PL emission peaks of the polymers were obviously quenched, suggesting that efficient photo induced charge transfer occur in the film, which was a prerequisite for achieving high photovoltaic performance.
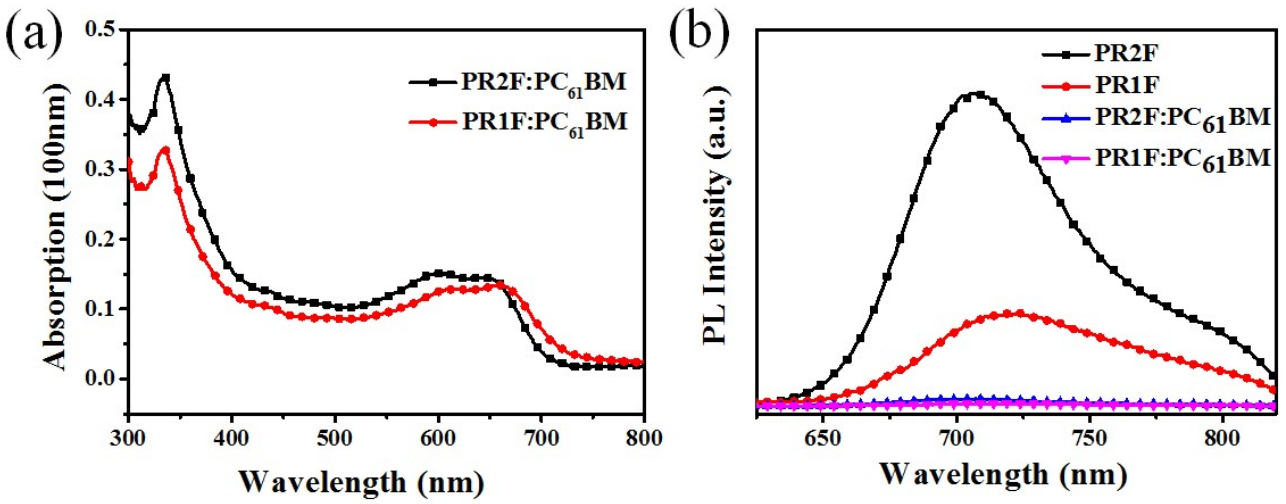

Figure 8. (a) Absorption spectra of the polymer: $\mathrm{PC}_{61} \mathrm{BM}(1: 1.5, \mathrm{w} / \mathrm{w})$ blend films processed with $2 \%$ 
DIO. (b) PL spectra of the pure polymers and the polymer:PC ${ }_{61} \mathrm{BM}$ blends respectively in the thin films.

\subsection{Morphology study}

The surface morphology of the photoactive layers was studied by tapping mode atomic force microscopy (AFM). Figure 9 shows the height and phase images of the as-cast and SVA blend films of PR2F:PC ${ }_{61} \mathrm{BM}$ and PR1F:PC ${ }_{61} \mathrm{BM}$. Both the PR2F:PC ${ }_{61} \mathrm{BM}$ and PR1F:PC 61 BM blend films exhibit well-developed interconnected network with nanoscale fibril structure. The AFM images in Figure 9 demonstrate that SVA produced PR2F:PC 61 BM and PR1F:PC ${ }_{61} \mathrm{BM}$ films with rather smooth surfaces, accompanied by a reduction in the root-mean-square (RMS) roughness from 7.08 to $3.59 \mathrm{~nm}$ for PR2F:PC 61 BM and from 8.34 to $5.65 \mathrm{~nm}$ for PR1F:PC ${ }_{61} \mathrm{BM}$. It is believed that such morphological change can facilitate charge separation and collection [31].
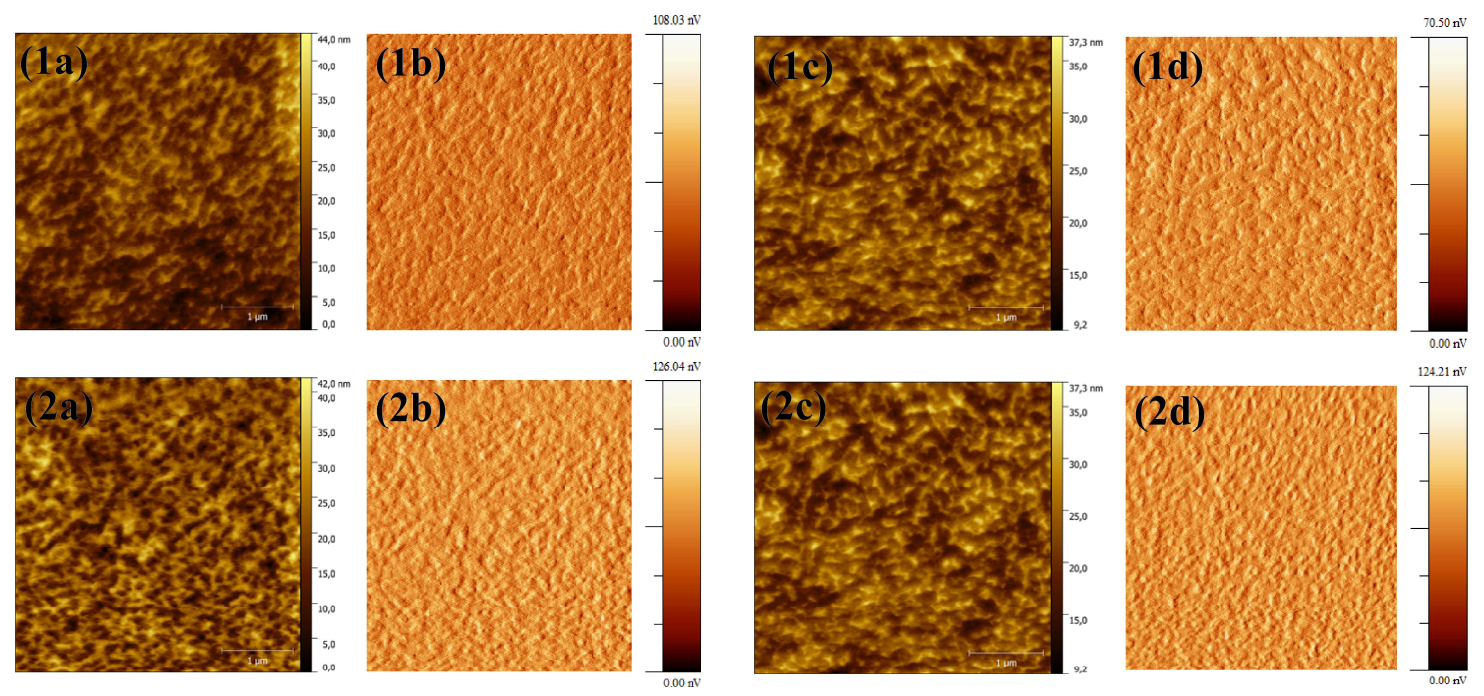

Figure 9. AFM topography height images. (1a, 2a and 1c, 2c) and the corresponding phase images (1b, 2b and 1d, 2d) of the polymers:PC ${ }_{61} \mathrm{BM}(1: 1.5$, w/w) blend films. PR2F (1a and 1c), PR1F (2a and 2c) without SVA. PR2F (1c and 1d), PR1F (2c and 2d) with SVA. 


\section{Experimental Section}

\subsection{Materials}

All chemicals were purchased from commercial sources and used without further purification, except that toluene was dried over $\mathrm{Na}$ /benzophenone ketyl and freshly distilled prior to use. All air and water sensitive reactions were performed under a nitrogen atmosphere. Monomers M1, M2, M3 and M4 were synthesized according to the literature methods [24,33]. PR2F and PR1F were synthesized by Stille polymerization. Synthesis details are described below.

4-bromo-7-(4-(2-octyldodecyl)thiophen-2-yl)-5,6-fluorobenzo[c][1,2,5]thiadiazole (M1): 4,7-Dibromo-5,6-difluorobenzo[c][1,2,5]thiadiazole $\quad\left(\begin{array}{llll}1.0 & \mathrm{~g}, & 3.03 & \mathrm{mmol}\end{array}\right)$, tributyl(4-(2-octyldodecyl)thiophen-2-yl)stannane (1.93 g, $2.95 \mathrm{mmol})$ and toluene (25 $\mathrm{mL}$ ), were added to a two-neck round flask and degassed with nitrogen for $15 \mathrm{~min}$. The catalyst $\mathrm{Pd}\left(\mathrm{PPh}_{3}\right)_{4}(0.21 \mathrm{~g}, 6 \mathrm{mmol} \%)$ was added quickly under a stream of nitrogen, and then the reaction mixture was purged with nitrogen again for $15 \mathrm{~min}$. Subsequently, the reaction mixture was heated to reflux for $48 \mathrm{~h}$ with stirring. The reaction mixture was then cooled to room temperature and extracted with dichloromethane and deionized water. The organic layer was dried over magnesium sulfate, and the solvent was removed. The crude product was purified with column chromatography and then the product was obtained as yellow solid (yield $=68 \%, 1.23 \mathrm{~g}) .{ }^{1} \mathrm{H}$ NMR $\left(\mathrm{CDCl}_{3}, 400 \mathrm{MHz}\right): \delta 8.08(\mathrm{~s}$, $1 \mathrm{H}), 7.22(\mathrm{~s}, 1 \mathrm{H}), 2.65(\mathrm{~d}, 2 \mathrm{H}, J=8.0 \mathrm{~Hz}), 2.05-1.95(\mathrm{~m}, 1 \mathrm{H}), 1.75-1.60(\mathrm{~m}, 2 \mathrm{H})$, $1.55-1.48(\mathrm{~m}, 2 \mathrm{H}), 1.38-1.16(\mathrm{~m}, 28 \mathrm{H}), 0.96-0.76(\mathrm{~m}, 6 \mathrm{H})$.

4-bromo-7-(4-(2-octyldodecyl)thiophen-2-yl)-5-fluorobenzo[c] [1,2,5]thiadiazole (M2): 4,7-Dibromo-5-difluorobenzo[c][1,2,5]thiadiazole $\quad(1.0 \quad \mathrm{~g}, \quad 3 \mathrm{mmol})$, tributyl(4-(2-octyldodecyl)thiophen-2-yl)stannane (1.93 g, $2.95 \mathrm{mmol})$ and toluene (25 $\mathrm{mL})$ were added to a two-neck round flask and degassed with nitrogen for $15 \mathrm{~min}$. The 
catalyst $\mathrm{Pd}\left(\mathrm{PPh}_{3}\right)_{4}(0.2 \mathrm{~g}, 6 \mathrm{mmol} \%)$ was added quickly under a stream of nitrogen, and then the reaction mixture was purged with nitrogen again for $15 \mathrm{~min}$. Subsequently, the reaction mixture was heated to reflux for $48 \mathrm{~h}$ with stirring. The reaction mixture was then cooled to room temperature and extracted with dichloromethane and deionized water. The organic layer was dried over magnesium sulfate, and the solvent was removed. The crude product was purified with column chromatography, and then the product was obtained as yellow solid (yield $=69 \%, 1.25 \mathrm{~g}) .{ }^{1} \mathrm{H}$ NMR $\left(\mathrm{CDCl}_{3}, 400 \mathrm{MHz}\right): \delta 7.95(\mathrm{~s}$, $1 \mathrm{H}), 7.69(\mathrm{~d}, 1 \mathrm{H}, J=8.0 \mathrm{~Hz}), 7.09(\mathrm{~s}, 1 \mathrm{H}), 2.62(\mathrm{~d}, 2 \mathrm{H}, J=8.0 \mathrm{~Hz}), 1.72-1.63(\mathrm{~m}, 1 \mathrm{H})$, 1.46-1.05 (m, 32H), 0.93-0.81 (m, 6H).

4-bromo-7-(5-bromo-4-(2-octyldodecyl)thiophen-2-yl)-5,6-difluorobenzo[c][1,2,5]thiadi azole (M3): A solution of monomer M1 (1.23 g, $2 \mathrm{mmol})$ in tetrahydrofuran (25 mL) was cooled to $0{ }^{\circ} \mathrm{C}$ in dark. N-bromosuccinimide $(0.39 \mathrm{~g}, 2.2 \mathrm{mmol})$ was added dropwise. The reaction mixture was warmed to room temperature, stirred overnight and concentrated in vacuum. The residue was purified by column chromatography (eluent: dichloromethane/petroleum ether) to get the product as an yellow solid $(1.25 \mathrm{~g}, 94 \%) .{ }^{1} \mathrm{H}$ NMR $\left(\mathrm{CDCl}_{3}, 400 \mathrm{MHz}\right): \delta 7.91(\mathrm{~s}, 1 \mathrm{H}), 2.58(\mathrm{~d}, 2 \mathrm{H}, J=8.0 \mathrm{~Hz}), 1.78-1.69(\mathrm{~m}, 1 \mathrm{H})$, $1.40-1.16(\mathrm{~m}, 32 \mathrm{H}), 0.91-0.81(\mathrm{~m}, 6 \mathrm{H})$.

4-bromo-7-(5-bromo-4-(2-octyldodecyl)thiophen-2-yl)-5-fluorobenzo[c][1,2,5]thiadiazol e (M4): A solution of monomer M2 (1.2 g, $2 \mathrm{mmol})$ in tetrahydrofuran $(25 \mathrm{~mL})$ was cooled to $0{ }^{\circ} \mathrm{C}$ in dark. N-bromosuccinimide $(0.39 \mathrm{~g}, 2.2 \mathrm{mmol})$ was added dropwise. The reaction mixture was warmed to room temperature, stirred overnight and concentrated in vacuum. The residue was purified by column chromatography (eluent: dichloromethane :petroleum ether ) to get the product as an yellow solid (1.20 g, 93\%). ${ }^{1} \mathrm{H}$ NMR $\left(\mathrm{CDCl}_{3}, 400 \mathrm{MHz}\right): \delta 7.74(\mathrm{~s}, 1 \mathrm{H}), 7.63(\mathrm{~d}, 1 \mathrm{H}, J=8.0 \mathrm{~Hz}), 2.57$ (d, 2H, $J=$ $8.0 \mathrm{~Hz}), 1.73(\mathrm{~m}, 1 \mathrm{H}), 5.54(\mathrm{~m}, 1 \mathrm{H}), 1.29-1.22(\mathrm{~m}, 32 \mathrm{H}), 0.87-0.83(\mathrm{~m}, 6 \mathrm{H})$.

PR2F: To a solution of M5 (0.17 mmol, $167 \mathrm{mg}), \mathrm{M} 3(0.17 \mathrm{mmol}, 103 \mathrm{mg})$ in anhydrous toluene $(15 \mathrm{~mL}), \mathrm{Pd}\left(\mathrm{PPh}_{3}\right)_{4}(11.8 \mathrm{mg}, 6 \mathrm{mmol} \%)$ were added. Then the mixture was 
stirred at $110{ }^{\circ} \mathrm{C}$ for 60 hours under nitrogen atmosphere. After cooling down to room temperature, the reaction mixture was precipitated in methanol and filtered through a Soxhlet thimble. The polymer was subjected to sequential Soxhlet extraction with acetone, hexane, and chloroform. The chloroform fraction was concentrated under reduced pressure and precipitated in methanol to obtain the resulting polymer $(180 \mathrm{mg}$, yield $=80 \%) . M_{\mathrm{n}}=24.9 \mathrm{kDa}, \mathrm{PDI}=3.31$.

PR1F: To a solution of monomers M5 $(0.167 \mathrm{~g}, 0.17 \mathrm{mmol})$ and M4 (0.115 g, $0.17 \mathrm{mmol})$ in anhydrous toluene $(15 \mathrm{~mL}), \mathrm{Pd}\left(\mathrm{PPh}_{3}\right)_{4}(0.012 \mathrm{~g}, 6 \mathrm{mmol} \%)$ were added. Then the mixture was stirred at $110{ }^{\circ} \mathrm{C}$ for 60 hours under nitrogen atmosphere. After cooling down to room temperature, the reaction mixture was precipitated in methanol and filtered through a Soxhlet thimble. The polymer was subjected to sequential Soxhlet extraction with acetone, hexane, chloroform The chloroform fraction was concentrated under reduced pressure and precipitated in methanol to obtain the resulting polymer $(175 \mathrm{mg}$, yield $=81 \%) . M_{\mathrm{n}}=61 \mathrm{kDa}, \mathrm{PDI}=1.92$.

\subsection{Characterization}

${ }^{1} \mathrm{H}$ NMR spectra were recorded using a Bruker Advance IIITM (400 $\left.\mathrm{MHz}\right)$ spectrometer in $\mathrm{CDCl}_{3}$ and ambient conditions. UV-vis absorption spectra were recorded at room temperature using a Shimadzu UV-2006 ultraviolet-visible spectroscopy. CV measurements were performed on a CHI660D electrochemical workstation under an argon atmosphere in a solution of ${ }^{n} \mathrm{Bu}_{4} \mathrm{NPF}_{6}(0.1 \mathrm{M})$ in acetonitrile at a scan rate of 50 $\mathrm{mV} \mathrm{s}^{-1}$ at ambient temperature with a three-electrode cell consisting of a Pt working electrode, a saturated calomel reference clectrode (SCE) and a Pt wire counter electrode. Polymer thin films were formed by drop-casting chloroform solution (analytical reagent, $1 \mathrm{mg} \mathrm{mL}^{-1}$ ) onto the working electrode, and then dried in the air. The platinum reference electrode was calibrated using a ferrocene/ferrocenium redox couple as an external 
standard, whose oxidation potential is set at $-4.8 \mathrm{eV}$ with respect to zero vacuum level, $\mathrm{HOMO}=-\left(E_{\text {ox }}^{\text {on }}-E_{1 / 2}, \mathrm{Fc}\right)+(-4.8) \mathrm{eV}, \mathrm{LUMO}=-\left(E_{\text {red }}^{\text {on }}-E_{1 / 2}, \mathrm{Fc}\right)+(-4.8) \mathrm{eV}$. Molecular weights and distributions of PR2F and PR1F were measured by gel permeation chromatography (GPC) method on Waters 1515 with polystyrenes as reference standard and THF as an eluent at $40{ }^{\circ} \mathrm{C}$. Thermal gravimetric analysis (TGA) measurements were performed on a STA-409 at a heating rate of $10{ }^{\circ} \mathrm{C} \min ^{-1}$ under a nitrogen atmosphere. Photoluminescence (PL) spectra of the polymers were characterized using Edinburgh Instruments FLS980. The surface roughness and morphology of thin films were characterized by using a tapping-mode atomic force microscope (AFM, Agilent 5400).

\subsection{Fabrication and characterization of solar cells}

ITO-coated glass substrates were cleaned by sonication in detergent, deionized water, acetone and isopropyl alcohol and dried under a nitrogen stream, $40 \mathrm{~nm}$ thick PEDOT:PSS was spin-coated onto the ITO, and then the substrate was baked at $120{ }^{\circ} \mathrm{C}$ for 15 min under air. The photoactive layer was subsequently prepared by spin coating a solution of the copolymer and $\mathrm{PC}_{61} \mathrm{BM}(1: 1.5, \mathrm{w} / \mathrm{w})$ in $\mathrm{CB}$ on the ITO/PEDOT:PSS electrode. The concentration of the blend solution was $20 \mathrm{mg} \mathrm{mL}^{-1}$. The photoactive layer was then methanol vapour annealed at $30^{\circ} \mathrm{C}$ for $15 \mathrm{~s}$. Finally, a layer of $1 \mathrm{~nm} \mathrm{LiF}$ and $100 \mathrm{~nm} \mathrm{Al} \mathrm{was} \mathrm{vacuum} \mathrm{evaporated} \mathrm{onto} \mathrm{the} \mathrm{photoactive} \mathrm{layer} \mathrm{through} \mathrm{a} \mathrm{shadow}$ mask in a vacuum of ca. $10^{-4} \mathrm{~Pa}$. The effective area of the device was $0.04 \mathrm{~cm}^{2}$. Current density-voltage $(J-V)$ characteristics of devices in dark and under illumination were measured using a programmable Keithley 2400 measurement source. The cells were illuminated by AM 1.5 G solar simulator (ABET Technologies Sun 3000 Solar Simulator) with reference to a standard Si cell calibrated with NREL at an irradiation intensity of $100 \mathrm{~mW} \mathrm{~cm} \mathrm{~cm}^{-2}$. External quantum efficiency (EQE) as a function of wavelength was recorded using ZOLIX CSC1011, where the light source was provided by an Ushio 
UXL-553Xenonshort arc lamp. The thicknesses of the active layers were measured by using a KLA Tencor D-120 profilometer.

\subsection{Hole and electron mobility}

Hole and electron mobility was measured by using the space charge limited current (SCLC) method with the device structure of ITO/PEDOT:PSS (30 $\mathrm{nm}) /$ polymer:PC $61 \mathrm{BM} / \mathrm{MoO}_{3}(10 \mathrm{~nm}) / \mathrm{Al}(100 \mathrm{~nm})$ and $\mathrm{ITO} / \mathrm{ZnO} /$ polymer:PC $61 \mathrm{BM} / \mathrm{LiF}$ $(1 \mathrm{~nm}) / \mathrm{Al}(100 \mathrm{~nm})$, respectively. The SCLC is described as: $J=9 \varepsilon_{o} \varepsilon_{r} \mu_{e} V^{2} / 8 d^{3}$, where $J$ is the current density, $\varepsilon_{\mathrm{r}}$ is the dieletric constant of the polymers, $\varepsilon_{\mathrm{o}}$ is the permittivity of the vacuum, $\mu_{\mathrm{e}}$ is the mobility, $d$ is the thickniss of the active layer, and $V$ is the internal potential in the device. The internal potential $\left(V=V_{\mathrm{appl}}-V_{\mathrm{bi}}-\mathrm{V}_{\mathrm{a}}\right.$, where $V_{\mathrm{appl}}$ is the applied voltage to the device, $V_{\text {bi }}$ is the built-in potential determined by electrode work function difference, and $V_{\mathrm{a}}$ is the voltage drop due to contact resistance and series resistance across the electrodes). The mobility was calculated from the slope of $J_{1 / 2}-V$ plots [33].

\section{Conclusion}

In this work, based on two asymmetric fluorinated BT-T units constructed D-A polymers, we reported two region asymmetric polymer donor materials PR2F and PR1F with three repeat units of A-D-A, $\pi-\mathrm{D}-\mathrm{A}$, and $\pi-\mathrm{D}-\pi$ along the polymer backbone and evaluated the photovoltaic performance in fullerene solar cells. The results showed that both the region asymmetric polymers had a low lying of HOMO energy level and then obtained the high $V_{\mathrm{OC}}$ of $\sim 1 \mathrm{~V}$ in both PR2F and PR1F devices. The relatively higher and balanced charge carrier mobilities of PR2F-based device gave rise to higher $J_{\mathrm{SC}}$ and FF than those of PR1F-based device. The best efficiency of the $\mathrm{P} 2: \mathrm{PC}_{61} \mathrm{BM}$ based devices 
revealed a superior PCE of $4.73 \%$, with a $V_{\mathrm{OC}}$ of $0.98 \mathrm{~V}$, and improved $J_{\mathrm{SC}}$ of $10.01 \mathrm{~mA}$ $\mathrm{cm}^{-2}$ and FF of 0.48 . These results indicate that the region asymmetric conjugated polymer is a promising class of materials for PSC applications, and it is significant to further understand the influence of polymer structure on optoelectronic properties.

Acknowledgements: This work was supported by the National Natural Science Foundation of China (Grant no. 61571317, 61775156, and 61475109), Key Research and Development (International Cooperation) Program of Shanxi (201603D421042), and Platform and Base Special Project of Shanxi (201605D131038).

Conflicts of Interest: The authors declare no conflict of interest.

\section{References}

1. Hao, M.; Li, X.; Shi, K.; Xie, D.; Zeng, X.; Fang, J.; Yu, G.; Yang, C. Highly efficient photovoltaics and field-effect transistors based on copolymers of mono-fluorinated benzothiadiazole and quaterthiophene: synthesis and effect of the molecular weight on device performance. Polym. Chem. 2015, 6, 6050-6057.

2. Ma, T.; Jiang, K.; Chen, S.; Hu, H.; Lin, H.; Li, Z.; Zhao, J.; Liu,Y.; Chang, Y.-M.; Hsiao, C.C.; Yan, H. Efficient low-bandgap polymer solar cells with high open-circuit voltage and good stability. Adv. Energy Mater. 2015, 5, 1501282.

3. Ye, C.; Wang, Y.; Bi, Z.; Guo, X.; Fan, Q.; Chen, J.; Ou, X.; Ma, W.; Zhang, M. High-performance organic solar cells based on a small molecule with thieno[3,2-b]thiophene as $\pi$-bridge. Org. Electron. 2018, 53, 273-279.

4. Xie, X.; Liu, G.; Cheng, G.; Liu, Z.; Lee, E.C. Improving performance of organic solar cells by supplying additional acceptors to surface of bulk-heterojunction layers. J. Mater. Chem. C 2018, 6, 2793-2800.

5. Park, C.G.; Park, G.E.; Lee, J.H.; Kim, A.; Kim, Y.U.; Park, S.Y.; Park, S.H.; Cho, M.J.; Choi, D.H. Regioisomeric $\pi$-conjugated terpolymers bearing carboxylate substituted thienothiophenyl quarterthiophene and their application to fullerene-free polymer solar cells. Polymer 2018, 146, 142-150.

6. Kan, B.; Feng, H.; Yao, H.; Chang, M.; Wan, X.; Li, C.; Hou, J.; Chen, Y. A chlorinated low-bandgap small-molecule acceptor for organic solar cells with $14.1 \%$ efficiency and low energy loss. Sci. China Chem. 2018, 61, 1307-1313. 
7. Kini, G.P.; Oh, S.; Abbas, Z.; Rasool, S.; Jahandar, M.; Song, C.E.; Lee, S.K.; Shin, W.S.; So, W.W.; Lee, J.C. Effects on photovoltaic performance of dialkyloxy-benzothiadiazole copolymers by varying the thienoacene donor. ACS Appl. Mater. Interfaces 2017, 9, 12617-12628.

8. Zhao, J.; Li, Y.; Yang, G.; Jiang, K.; Lin, H.; Ade, H.; Ma, W.; Yan, H. Efficient organic solar cells processed from hydrocarbon solvents. Nat. Energy 2016, 1, 15027.

9. Liu, Y.; Zhao, J.; Li, Z.; Mu, C.; Ma, W.; Hu, H.; Jiang, K.; Lin, H.; Ade, H.; Yan, H. Aggregation and morphology control enables multiple cases of high-efficiency polymer solar cells. Nat. Commun. 2014, 5, 5293.

10. Zhang, S.; Yang, B.; Liu, D.; Zhang, H.; Zhao, W.; Wang, Q.; He, C.; Hou, J. Correlations among chemical structure, backbone conformation, and morphology in two highly efficient photovoltaic polymer materials. Macromolecules 2015, 49, 120-126.

10. Yue, W.; Ashraf, R.S.; Nielsen, C.B.; Collado-Fregoso, E.; Niazi, M.R.; Yousaf, S.A.; Kirkus, M.; Chen, H.Y.; Amassian, A.; Durrant, J.R.; McCulloch, I. A thieno[3,2-b]benzothiophene isoindigo building block for additive- and annealing-free high-performance polymer solar cells. Adv. Mater. 2015, 27, 4702-4707.

12. Vohra, V.; Kawashima, K.; Kakara, T.; Koganezawa, T.; Osaka, I.; Takimiya, K.; Murata, H. Efficient inverted polymer solar cells employing favourable molecular orientation. Nat. Photonics 2015, 9, 403-408.

13. Jo, J.W.; Bae, S.; Liu, F.; Russell, T.P.; Jo, W.H. Comparison of two D-A type polymers with each being fluorinated on D and A unit for high performance solar cells. Adv. Funct. Mater. 2015, $25,120-125$.

14. Wang, M.; Cai, D.; Yin, Z.; Chen, S.C.; Du, C.-F.; Zheng, Q. Asymmetric-2015indenothiophene-based copolymers for bulk heterojunction solar cells with 9.14\% efficiency. Adv. Mater. 2016, 28, 3359-3365.

15. Jeon, S.J.; Lee, T.H.; Han, Y.-W.; Moon, D.K. Design and synthesis of $2 \mathrm{D} \mathrm{A}_{1}-\pi-\mathrm{A}_{2}$ copolymers impact on fullerene network for efficient polymer solar cells. Polymer 2018, 149, 85-95.

16. Zeng, Z.; Zhang, Z.; Zhao, B.; Liu, H.; Sun, X.; Wang, G.; Zhang, J.; Tan, S. Rational design of a difluorobenzo[c]cinnoline-based low-bandgap copolymer for high-performance polymer solar cells. J. Mater. Chem. A 2017, 5, 7300-7304.

17 Li, Z.; Wang, X.; Ren, J.; Gan, G.; Liu, C.; Sun, Q.; Wang, H.; Hao, Y. Fabrication of benzothiadiazole-benzodithiophene-based random copolymers for efficient thick-film polymer solar cells via a solvent vapor annealing approach. J. Mater. Chem. C 2018, 6, 4555-4564.

18. Li, W.; Hendriks, K.H.; Furlan, A.; Zhang, A.; Wienk, M.M.; Janssen, R.A. A regioregular terpolymer comprising two electron-deficient and one electron-rich unit for ultra small band gap solar cells. Chem. Commun. 2015, 51, 4290-4293.

19. Wang, J.; Wang, S.; Duan, C.; Colberts, F.J.M.; Mai, J.; Liu, X.; Jia, X.-E.; Lu, X.; Janssen, R.A.J.; Huang, F.; Cao, Y. Conjugated polymers based on difluorobenzoxadiazole toward practical application of polymer solar cells. Adv. Energy Mater. 2017, 7, 1702033.

20. Cao, J.; Zuo, C.; Yu, J.; Tang, Z. D-A copolymers based on lactam acceptor unit and thiophene derivatives for efficient polymer solar cells. Dyes Pigments 2017, 139, 201-207. 
21. He, M.; Li, M.; Dong, X.; Tian, H.; Tong, H.; Liu, J.; Xie, Z.; Geng, Y.; Wang, F. A difluorobenzothiadiazole-based conjugated polymer with alkylthiophene as the side chains for efficient, additive-free and thick-film polymer solar cells. J. Mater. Chem. A 2017, 5, 20473-20481.

22. Heo, H.; Kim, H.; Lee, D.; Jang, S.; Ban, L.; Lim, B.; Lee, J.; Lee, Y. Regioregular D1-A-D2-A terpolymer with controlled thieno[3,4-b]thiophene orientation for high-efficiency polymer solar cells processed with nonhalogenated solvents. Macromolecules 2016, 49, 3328-3335.

23. Xin, Y.; Zeng, G.; Zhang, J.; Zhao, X.; Yang, X. A new copolymer based on a D- $\pi-A$ or D-A- $\pi$ repeat unit for polymer solar cells employing non-halogenated solvents. J. Mater. Chem. A 2018, 6, 9561-9568.

24. Zhou, C.; Chen, Z.; Zhang, G.; McDowell, C.; Luo, P.; Jia, X.; Ford, M.J.; Wang, M.; Bazan,G.C.; Huang, F.; Cao, Y. Toward high efficiency polymer solar cells: rearranging the backbone units into a readily accessible random tetrapolymer. Adv. Energy Mater. 2018, 8, 1701668.

25. Liu, Q.; Li, C.; Jin, E.; Lu, Z.; Chen, Y.; Li, F.; Bo, Z. 9-Arylidene-9H-fluorene-containing polymers for high efficiency polymer solar cells. ACS Appl. Mater. Interfaces 2014, 6, 1601-1607.

26. Sun, Y.; Seifter, J.; Huo, L.; Yang, Y.; Hsu, B.B.Y.; Zhou, H.; Sun, X.; Xiao, S.; Jiang, L.; Heeger, A.J. High-performance solution-processed small-molecule solar cells based on a dithienogermole-containing molecular donor. Adv. Energy Mater. 2015, 5, 1400987.

27. Stenta, C.; Molina, D.; Viterisi, A.; Montero-Rama, M.P.; Rama, M.; Pla, S.; Cambarau, W.; Fernández-Lázaro, F.; Palomares, E. Diphenylphenoxy-Thiophene-PDI Dimers as Acceptors for OPV Applications with Open Circuit Voltage Approaching 1 Volt. Nanomaterials 2018, 8, 211.

28. Lu, Z.; Liu, W.; Li, J.-J.; Fang, T.; Li, W.-N.; Zhang,J.-C.; Feng, F.; Li, W.-H. The Influence of Fluorination on Nano-Scale Phase Separation and Photovoltaic Performance of Small Molecular/PC ${ }_{71} \mathrm{BM}$ Blends. Nanomaterials 2016, 6, 80.

29. Cui, C.; He, Z.; Wu, Y.; Cheng, X.; Wu, H.; Li, Y.; Cao, Y.; Wong, W.-Y. High-performance polymer solar cells based on a 2D-conjugated polymer with an alkylthio side-chain. Energ. Environ. Sci. 2016, 9, 885-891.

30. Bao, X.; Zhang, Y.; Wang, J.; Zhu, D.; Yang, C.; Li, Y.; Yang, C.; Xu, J.; Yang, R. High extinction coefficient thieno[3,4-b]thiophene-based copolymer for efficient fullerene-free solar cells with large current density. Chem. Mater. 2017, 29, 6766-6771.

31. Gu, C.; Liu, D.; Wang, J.; Niu, Q.; Gu, C.; Shahid, B.; Yu, B.; Cong, H.; Yang, R. Alkylthienyl substituted asymmetric 2D BDT and DTBT-based polymer solar cells with a power conversion efficiency of 9.2\%. J. Mater. Chem. A 2018, 6, 2371-2378.

32. Price, S.C.; Stuart, A.C.; Yang, L.; Zhou, H.; You, W. Fluorine substituted conjugated polymer of medium band gap yields 7\% efficiency in polymer-fullerene solar cells. J. Am. Chem. Soc. 2011, 133, 4625-4631.

33. Dang, D.; Wang, X.; Zhi, Y.; Meng, L.; Bao, X.; Yang, R.; Zhu, W. Synthesis and characterization of D-A-A type regular terpolymers with narrowed band-gap and their application in high performance polymer solar cells. Org. Electron. 2016, 32, 237-243. 